\title{
Significant Drivers of Growth in Africa
}

\author{
Oleg Badunenko, Daniel J. Henderson, Romain Houssa
}

\begin{abstract}
We employ bootstrap techniques in a production frontier framework to provide statistical inference for each component in the decomposition of labor productivity growth, which has essentially been ignored in this literature. We show that only two of the four components (efficiency changes and human capital accumulation) have significantly contributed to growth in Africa. Although physical capital accumulation is the largest force, it is not statistically significant on average. Thus, ignoring statistical significance would falsely identify physical capital accumulation as a major driver of growth in Africa when it is not.

JEL classification: C14, C15, O10, O40

Keywords: Africa, Bootstrap, Growth, Production Frontier
\end{abstract}




\section{Introduction}

The overall growth performance of most African countries has been poor compared to that of other developing countries. In particular, the average annual African per capita real GDP growth has hardly surpassed two percent, while East Asian countries, for instance, have been experiencing impressive growth rates in the ranges of four to eight percent. A number of studies analyze this weak performance. For instance, in terms of the proximate causes of this slow growth, the literature, employing the standard growth accounting method, often argues that low total factor productivity is the main impediment to African growth (see, for example, Ndulu and O'Connell 1999, 2009, Hoeffler 2002, Tahari et al. 2004, Bosworth and Collins 2003, Artadi and Sala-i Martin 2003). Physical and human capital accumulation, on the other hand, have been identified to facilitate growth in Africa (e.g., Berthelemy and Söderling 2001, Tahari et al. 2004). However, their contributions are smaller compared to that of other developing countries (Ndulu and O'Connell 2009, Senhadji 2000).

Another line of research has relied on regression techniques and find the following fundamental causes of the weak African growth record: geographical constraints in the forms of high transaction costs, lower soil quality and exposure to diseases (Gallup et al. 1999, Bloom and Sachs 1998, Sachs et al. 1995, Sachs and Warner 1997, Masters and McMillan 2001); bad governance characterized by inappropriate trade and macroeconomic stabilization and adjustment policies, ineffective policies towards health and demographic challenges, and policy distortions that favored interest groups (Artadi and Sala-i Martin 2003, Bates 1983, Sachs and Warner 1997, Easterly and Levine 1997, Ndulu and O'Connell 1999, Collier and Gunning 1999b, Collier and O'Connell 2008); weak institutional capacity, ethnic fragmentation, conflicts and civil wars (Acemoglu et al. 2005, Rodrik et al. 2004, Acemoglu et al. 2001, 
Nunn 2008, Collier and Hoeffler 2004, Easterly and Levine 1997, Rodrik 1999, Collier 1999).

In this study, we investigate the sources of productivity growth in Africa by using a production frontier framework. Noteworthy examples in this line include Färe et al. (1994), Kumar and Russell (2002) and Henderson and Russell (2005, HR hereafter). These and follow-up studies perform a cross-country analysis of labor productivity growth by decomposing it into different sources (see also Badunenko, Henderson and Zelenyuk 2008, Badunenko, Henderson and Russell 2013, Badunenko and Romero-Ávila 2013). Different from these past studies, we maintain that African countries have access to their own production frontier, not necessarily to the world production frontier, thus benchmarking African economies against one another. $^{1}$ Further, studies that use nonparametric production frontier measurement have largely ignored the issue of statistical inference when identifying the sources of labor productivity growth. We therefore make use of bootstrap methods (Simar and Wilson 1999) to provide statistical inference regarding the growth components. The only related reference we are aware of is Jeon and Sickles (2004), who apply the Simar and Wilson (1999) method to test for significance of Malmquist indices in a cross-country analysis. However, their focus is on environmental factors and their approach does not analyze the role of either physical or human capital accumulation.

Our results show that, over the 1970 - 2007 period, only human capital accumulation and efficiency changes have, on average, statistical and significant effects on African growth. Although physical capital accumulation is the largest component on average, it is not statistical significant. Therefore, if we were to ignore statistical

\footnotetext{
${ }^{1}$ For example, Sickles (2012) advocates for the existence of separate production frontiers. Similarly, Grosskopf and Self (2006) analyze Southeast Asian economies in isolation from the rest of the world.
} 
inference, we would falsely identify physical capital accumulation as a major driver of economic growth in the region.

The remainder of this paper is as follows: Section 2 provides a description of the quadripartite decomposition of productivity growth and the bootstrap procedure used to conduct inference of the components. Section 3 describes the data. Section 4 presents the empirical findings and Section 5 concludes.

\section{Methodology}

\subsection{Data Envelopment Analysis}

In this section, we follow the methodology in HR to construct African production frontier and retrieve efficiency scores of individual countries. More specifically, we use a nonparametric approach to efficiency measurement, Data Envelopment Analysis (DEA), which rests on assumptions of free disposability to envelope the data in the smallest convex cone, the upper boundary of which is the "best-practice" frontier. The distance from an observation to such cone then represents the measure of technical efficiency. DEA is an approach that allows data to tell where the frontier lies without specifying the functional form of the technology (see Kneip et al. (1998) for a proof of consistency for the DEA estimator, as well as Kneip et al. (2008) for its limiting distribution).

We specify technology to contain four macroeconomic variables: aggregate output and three aggregate inputs - labor, physical capital, and human capital. Let $\left\langle Y_{i t}, K_{i t}, L_{i t}, H_{i t}\right\rangle, t=1,2, \ldots, T, i=1,2, \ldots, N$, represent $T$ observations on these four variables for each of the $N$ countries. Finally, we adopt a standard approach in the literature (e.g. Lucas 1988, Klenow and Bils 2000, Hall and Jones 1999) and assume that human capital enters the technology as a multiplicative augmentation of 
physical labor input, so that our $N T$ observations are $\left\langle Y_{i t}, K_{i t}, \hat{L}_{i t}\right\rangle, t=1,2, \ldots, T$, $i=1,2, \ldots, N$, where $\hat{L}_{i t}=L_{i t} H_{i t}$ is the amount of labor input measured in effective units in country $i$ at time $t$. This labor-augmenting human capital specification reflects the idea that human capital captures the efficiency units of labour embedded in raw labour; (see Weil 2008, chapter 6) for a textbook exposition. ${ }^{2}$

The constant returns to scale technology in period $t$ is constructed by using all the data up to that point in time as

$$
\mathcal{T}_{t}=\left\{\begin{array}{c}
\langle Y, \hat{L}, K\rangle \in \Re_{+}^{3} \mid Y \leq \sum_{\tau \leq t} \sum_{i} z_{i \tau} Y_{i \tau}, \hat{L} \geq \sum_{\tau \leq t} \sum_{i} z_{i \tau} \hat{L}_{i \tau}, \\
K \geq \sum_{\tau \leq t} \sum_{i} z_{i \tau} K_{i \tau}, z_{i \tau} \geq 0 \forall i, \tau
\end{array}\right\}
$$

where $z_{i \tau}$ are the activity levels.

The Farrell (output-based) efficiency score for country $i$ at time $t$ is defined by

$$
e\left(Y_{i t}, \hat{L}_{i t}, K_{i t}\right)=\min \left\{\lambda \mid\left\langle Y_{i t} / \lambda, \hat{L}_{i t}, K_{i t}\right\rangle \in \mathcal{T}_{t}\right\}
$$

This score is the inverse of the maximal proportional amount that output $Y_{i t}$ can be expanded while remaining technologically feasible, given the technology and input quantities. It is less than or equal to unity and takes the value of unity if and only if the it observation is on the period-t production frontier. In our special case of a scalar output, the output-based efficiency score is simply the ratio of actual to potential output evaluated at the actual input quantities.

\footnotetext{
${ }^{2}$ An alternative specification is the human-capital augmented Solow model where human capital enters the production function as an additional ordinary input, next to physical capital and raw labor (Mankiw et al. 1992). However, this type of formulation is not micro-founded (see Acemoglu 2009, chap. 3 and chap. 10 for a discussion on this issue).
} 


\subsection{Quadripartite Decomposition}

We again follow the approach of HR to decompose productivity growth into components attributable to (1) changes in efficiency (technological catch-up), (2) technological change, (3) capital deepening (increases in the capital-labor ratio), and (4) human capital accumulation. Under the constant returns to scale assumption we construct the production frontiers in the $\hat{y} \times \hat{k}$ space, where $\hat{y}=Y / \hat{L}$ and $\hat{k}=K / \hat{L}$ are the ratios of output and capital, respectively, to effective labor. Letting $b$ and $c$ stand for the base period and current period respectively, the potential outputs per effective unit of labor in the two periods are defined by $\bar{y}_{b}\left(\hat{k}_{b}\right)=\hat{y}_{b} / e_{b}$ and $\bar{y}_{c}\left(\hat{k}_{c}\right)=\hat{y}_{c} / e_{c}$, where $e_{b}$ and $e_{c}$ are the values of the efficiency scores in the respective periods as calculated in Eq. (2) above. Hence,

$$
\frac{\hat{y}_{c}}{\hat{y}_{b}}=\frac{e_{c}}{e_{b}} \cdot \frac{\bar{y}_{c}\left(\hat{k}_{c}\right)}{\bar{y}_{b}\left(\hat{k}_{b}\right)} .
$$

Let $\tilde{k}_{c}=K_{c} /\left(L_{c} H_{b}\right)$ denote the ratio of capital to labor measured in effective units under the counterfactual assumption that human capital had not changed from its base period and $\tilde{k}_{b}=K_{b} /\left(L_{b} H_{c}\right)$ the ratio of capital to labor measured in effective units under the counterfactual assumption that human capital were equal to its current-period level. Then $\bar{y}_{b}\left(\tilde{k}_{c}\right)$ and $\bar{y}_{c}\left(\tilde{k}_{b}\right)$ are the potential output per effective unit of labor at $\tilde{k}_{c}$ and $\tilde{k}_{b}$ using the base-period and current-period technologies, respectively. By multiplying the numerator and denominator of Eq. (3) alternatively by $\bar{y}_{b}\left(\hat{k}_{c}\right) \bar{y}_{b}\left(\tilde{k}_{c}\right)$ and $\bar{y}_{c}\left(\hat{k}_{b}\right) \bar{y}_{c}\left(\tilde{k}_{b}\right)$, we obtain two alternative decompositions of the growth of $\hat{y}$

$$
\frac{\hat{y}_{c}}{\hat{y}_{b}}=\frac{e_{c}}{e_{b}} \cdot \frac{\bar{y}_{c}\left(\hat{k}_{c}\right)}{\bar{y}_{b}\left(\hat{k}_{c}\right)} \cdot \frac{\bar{y}_{b}\left(\tilde{k}_{c}\right)}{\bar{y}_{b}\left(\hat{k}_{b}\right)} \cdot \frac{\bar{y}_{b}\left(\hat{k}_{c}\right)}{\bar{y}_{b}\left(\tilde{k}_{c}\right)},
$$

and

$$
\frac{\hat{y}_{c}}{\hat{y}_{b}}=\frac{e_{c}}{e_{b}} \cdot \frac{\bar{y}_{c}\left(\hat{k}_{b}\right)}{\bar{y}_{b}\left(\hat{k}_{b}\right)} \cdot \frac{\bar{y}_{c}\left(\hat{k}_{c}\right)}{\bar{y}_{c}\left(\tilde{k}_{b}\right)} \cdot \frac{\bar{y}_{c}\left(\tilde{k}_{b}\right)}{\bar{y}_{c}\left(\hat{k}_{b}\right)} .
$$


The growth of productivity, $y_{t}=Y_{t} / L_{t}$, can be decomposed into the growth of output per effective unit of labor and the growth of human capital, as follows:

$$
\frac{y_{c}}{y_{b}}=\frac{H_{c}}{H_{b}} \cdot \frac{\hat{y}_{c}}{\hat{y}_{b}}
$$

Combining Eq. (4) and (5) with (6), we obtain

$$
\begin{aligned}
\frac{y_{c}}{y_{b}} & =\frac{e_{c}}{e_{b}} \cdot \frac{\bar{y}_{c}\left(\hat{k}_{c}\right)}{\bar{y}_{b}\left(\hat{k}_{c}\right)} \cdot \frac{\bar{y}_{b}\left(\tilde{k}_{c}\right)}{\bar{y}_{b}\left(\hat{k}_{b}\right)} \cdot\left[\frac{\bar{y}_{b}\left(\hat{k}_{c}\right)}{\bar{y}_{b}\left(\tilde{k}_{c}\right)} \cdot \frac{H_{c}}{H_{b}}\right] \\
& \equiv E F F \times T E C H_{c} \times K A C C_{b} \times H A C C_{b},
\end{aligned}
$$

and

$$
\begin{aligned}
\frac{y_{c}}{y_{b}} & =\frac{e_{c}}{e_{b}} \cdot \frac{\bar{y}_{c}\left(\hat{k}_{b}\right)}{\bar{y}_{b}\left(\hat{k}_{b}\right)} \cdot \frac{\bar{y}_{c}\left(\hat{k}_{c}\right)}{\bar{y}_{c}\left(\tilde{k}_{b}\right)} \cdot\left[\frac{\bar{y}_{c}\left(\tilde{k}_{b}\right)}{\bar{y}_{c}\left(\hat{k}_{b}\right)} \cdot \frac{H_{c}}{H_{b}}\right] \\
& \equiv E F F \times T E C H_{b} \times K A C C_{c} \times H A C C_{c} .
\end{aligned}
$$

Eq. (7) and (8) decompose the growth of labor productivity in the two periods into changes in efficiency, technology, the capital-labor ratio, and human capital accumulation. The decomposition in Eq. (4) measures technological change by the shift in the frontier in the output direction at the current-period capital to effective labor ratio, whereas the decomposition in Eq. (5) measures technological change by the shift in the frontier in the output direction at the base-period capital to effective labor ratio. Similarly, Eq. (7) measures the effect of physical and human capital accumulation along the base-period frontier, whereas Eq. (8) measures the effect of physical and human capital accumulation along the current-period frontier.

These two decompositions do not yield the same results unless the technology is Hicks neutral. In other words, the decomposition is path dependent. This ambiguity is resolved by adopting the "Fisher Ideal" decomposition, based on geometric 
averages of the two measures of the effects of technological change, capital deepening and human capital accumulation and obtained mechanically by multiplying the numerator and denominator of Eq. (3) by $\left(\bar{y}_{b}\left(\hat{k}_{c}\right) \bar{y}_{b}\left(\tilde{k}_{c}\right)\right)^{1 / 2}\left(\bar{y}_{c}\left(\hat{k}_{b}\right) \bar{y}_{c}\left(\tilde{k}_{b}\right)\right)^{1 / 2}$ :

$$
\begin{aligned}
\frac{y_{c}}{y_{b}} & =E F F \times\left(T E C H_{b} \cdot T E C H_{c}\right)^{1 / 2} \times\left(K A C C_{b} \cdot K A C C_{c}\right)^{1 / 2} \times\left(H A C C_{b} \cdot H A C C_{c}\right)^{1 / 2} \\
& \equiv E F F \times T E C H \times K A C C \times H A C C .
\end{aligned}
$$

\section{$2.3 \quad$ Statistical inference}

One major issue with the approach of HR and others in this line of research is that it ignores the issue of statistical significance of the components of labor productivity growth. Indeed, the individual and average components found in HR and related papers are point estimates; $\widehat{E F F}, T \widehat{E C} H, \widehat{K A C} C$, and $\widehat{H A C} C$ in Eq. (9) are calculated using the efficiency scores that are measured relative to the finite sample DEA estimate of the true and unobserved frontier. Using the finite sample estimate implies that the efficiency scores and consequently the components of the quadripartite decomposition are subject to sampling variation of the estimated frontier.

Simar and Wilson (1998) were the first to use bootstrap methods to analyze the sensitivity of efficiency scores relative to such sampling variations. Simar and Wilson (1999) furthered this idea to estimate the sampling distribution and confidence intervals for Malmquist productivity indices (a measure of productivity change) and its components. We employ a smoothed bootstrap procedure to provide statistical inference on the components of the quadripartite decomposition.

We first apply the DEA estimator introduced in Eq. (2) to the original observed samples in base $\left(S_{b}\right)$ and current $\left(S_{c}\right)$ time periods, $S_{b}=\left\langle Y_{i b}, \hat{L}_{i b}, K_{i b}\right\rangle_{i=1}^{N}$ and $S_{c}=\left\langle Y_{i c}, \hat{L}_{i c}, K_{i c}\right\rangle_{i=1}^{N}$ under the technology defined in Eq. (1) to obtain estimates 
of the efficiency scores $\boldsymbol{E}_{b}=\left\langle\widehat{e}_{i b}\right\rangle_{i=1}^{N}$ and $\boldsymbol{E}_{c}=\left\langle\widehat{e}_{i c}\right\rangle_{i=1}^{N}$. We then calculate the potential outputs per effective units of labor that appear in Eq. (7) and (8) and compute the four components of the decomposition in Eq. (9): $\widehat{E F F}, T \widehat{E C H}$, $\widehat{K A C} C$, and $\widehat{H A C} C$.

Providing statistical inference on these components involves generating bootstrap samples in base $\left(S_{b}^{*}\right)$ and current $\left(S_{c}^{*}\right)$ time periods. Simar and Wilson (1998) have shown that the naïve bootstrap, i.e. sampling from the empirical distribution of the data $S_{b}$ and $S_{c}$, or equivalently from the efficiency scores, $\boldsymbol{E}_{b c}=\left[\boldsymbol{E}_{b} \boldsymbol{E}_{c}\right]$, will yield inconsistent results because the efficiency score is truncated at one. Using the reflection method and the smoothed bootstrap results in consistent estimation of confidence intervals (see Silverman 1986). We discuss both the reflection and the smoothing techniques in the bivariate (two periods) case in greater detail below.

\subsubsection{Bivariate kernel density estimation of efficiency scores}

Let $\boldsymbol{E}_{b c i}$ be the $i$ th row of the $(N \times 2)$ matrix $\boldsymbol{E}_{b c}$, the columns of which being $\boldsymbol{E}_{b}$ and $\boldsymbol{E}_{c}$. Given sample realizations, $\boldsymbol{E}_{b c}=\left\{\boldsymbol{E}_{b c 1}, \boldsymbol{E}_{b c 2}, \ldots, \boldsymbol{E}_{b c N}\right\}^{\prime}$, from a population with unknown bivariate density $f$, a bivariate nonparametric estimate of the joint density that accounts for the possibility of the temporal correlation of $\boldsymbol{E}_{b c}$ is given by

$$
\hat{f}\left(\boldsymbol{e}_{b c}, h\right)=\frac{1}{N h^{2}} \sum_{i=1}^{N} K_{h}\left(\boldsymbol{E}_{b c i}, \boldsymbol{e}_{b c}\right),
$$

where $\boldsymbol{e}_{b c}=\left[e_{b} e_{c}\right]$ is of dimension $(1 \times 2), K_{h}(\cdot, \cdot)$ is the bivariate kernel function and bandwidth $h$ is the smoothing parameter (e.g., see Henderson and Parmeter (2014)). As a kernel function $K_{h}(\cdot, \cdot)$, one might use different choices for the bivariate (i) non-negative, (ii) radially symmetric, (iii) unimodal probability density function that integrates to one. We use the standard bivariate normal density 
function that is scaled to have the same covariance matrix as the data

$$
\begin{array}{r}
K_{h}\left(\boldsymbol{V} \boldsymbol{U}_{i}, \boldsymbol{v u}\right)=\frac{1}{2 \pi \widehat{\sigma}_{v} \widehat{\sigma}_{u} \sqrt{1-\widehat{\rho}_{v u}^{2}}} \exp \left\{-\frac{1}{2 h^{2}\left(1-\widehat{\rho}_{v u}^{2}\right)}\left[\left(\frac{V_{i}-v}{\widehat{\sigma}_{v}}\right)^{2}-\right.\right. \\
\left.\left.-2 \widehat{\rho}_{v u} \frac{\left(V_{i}-v\right)}{\widehat{\sigma}_{v}} \frac{\left(U_{i}-u\right)}{\widehat{\sigma}_{u}}+\left(\frac{U_{i}-u}{\widehat{\sigma}_{u}}\right)^{2}\right]\right\},
\end{array}
$$

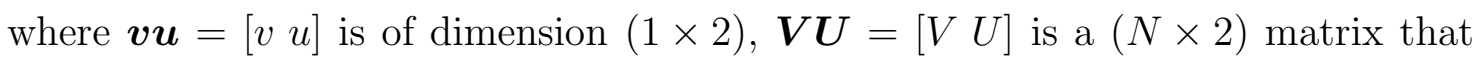
has vectors $V$ and $U$ as its columns, $\widehat{\rho}_{v u}$ is the estimated correlation coefficient of $V$ and $U$, and $\widehat{\sigma}_{v}^{2}$ and $\widehat{\sigma}_{v}^{2}$ are the estimated variances of $V$ and $U$. We use a single smoothing parameter $h=N^{-1 / 6}$ as a bandwidth for the bivariate data since we scale the kernel function to have the same covariance matrix as the estimated covariance matrix of the original data (see Silverman 1986, p. 86-87). Since the DEA efficiency scores are truncated at one, the density estimate using Eq. (10) will be inconsistent and asymptotically biased. In the univariate case (e.g. where we have the base period only), this truncation can be overcome by reflecting the truncated data points $\left\{e_{i b}\right\}_{i=1}^{N}$ in the boundary (i.e. about one), $\left\{2-e_{i b}\right\}_{i=1}^{N}$, and estimating the density using the resulting set of $2 N$ data points, $\left\{e_{i b} 2-e_{i b}\right\}_{i=1}^{N}$ (see Silverman 1986, p. 29-32). However, we have a bivariate case and hence there are two truncations, in base and current periods, which yield different combinations of the reflections

$$
\boldsymbol{E}_{b c}^{R}=\left[\begin{array}{cc}
\boldsymbol{E}_{b} & \boldsymbol{E}_{c} \\
2-\boldsymbol{E}_{b} & 2-\boldsymbol{E}_{c} \\
2-\boldsymbol{E}_{b} & \boldsymbol{E}_{c} \\
\boldsymbol{E}_{b} & 2-\boldsymbol{E}_{c}
\end{array}\right]
$$

The estimated covariance matrix of the columns of $\boldsymbol{E}_{b c}$ (as well as of the reflected data, $\left.\left[2-\boldsymbol{E}_{b} 2-\boldsymbol{E}_{c}\right]\right)$ is defined as

$$
\widehat{\mathbf{\Sigma}}=\left[\begin{array}{cc}
\widehat{\sigma}_{b}^{2} & \widehat{\sigma}_{b c} \\
\widehat{\sigma}_{b c} & \widehat{\sigma}_{c}^{2}
\end{array}\right]
$$


which measures the time correlation of the efficiency scores in the two periods. The estimated covariance matrix of $\left[2-\boldsymbol{E}_{b} \boldsymbol{E}_{c}\right]$ and $\left[\boldsymbol{E}_{b} 2-\boldsymbol{E}_{c}\right]$ is given by

$$
\widehat{\Sigma}^{R}=\left[\begin{array}{cc}
\widehat{\sigma}_{b}^{2} & -\widehat{\sigma}_{b c} \\
-\widehat{\sigma}_{b c} & \widehat{\sigma}_{c}^{2}
\end{array}\right]
$$

Let $\boldsymbol{E}_{b c j}^{R}$ be the $j$ th row of the $(4 N \times 2)$ matrix $\boldsymbol{E}_{b c}^{R}$. The bivariate nonparametric estimate of the joint density of the $4 N$ reflected data points of $\boldsymbol{E}_{b c}^{R}$ is given by

$$
\widehat{g}\left(\boldsymbol{e}_{b c}, h\right)=\frac{1}{4 N h^{2}}\left[\sum_{j=1}^{2 N} K_{h}\left(\boldsymbol{E}_{b c j}^{R}, \boldsymbol{e}_{b c}\right)+\sum_{j=2 N+1}^{4 N} K_{h}\left(\boldsymbol{E}_{b c j}^{R}, \boldsymbol{e}_{b c}\right)\right]
$$

Note that the estimate in Eq. (15) is the additive kernel estimate, where the first term is the bivariate normal density function with the estimated covariance matrix $\widehat{\Sigma}$ and the second term is the bivariate normal density function with the estimated covariance matrix $\widehat{\Sigma}^{R}$. More specifically, the correlation coefficient in Eq. (11) is defined as: $\widehat{\rho}_{v u}=\widehat{\sigma}_{b c} / \widehat{\sigma}_{b} \widehat{\sigma}_{c}$ for $j=1, \ldots, 2 N$ and $\widehat{\rho}_{v u}=-\widehat{\sigma}_{b c} / \widehat{\sigma}_{b} \widehat{\sigma}_{c}$ for $j=$ $2 N+1, \ldots, 4 N$. The consistent estimate of the density of the original data $\boldsymbol{E}_{b c}$ is given by

$$
\widehat{g}^{*}\left(\boldsymbol{e}_{b c}, h\right)= \begin{cases}4 \widehat{g}\left(\boldsymbol{e}_{b c}, h\right), & \text { for } e_{b} \leq 1, e_{c} \leq 1 \\ 0, & \text { otherwise }\end{cases}
$$

\subsubsection{Smoothed bootstrap}

We do not actually have to estimate the density in (16). The following smoothed bootstrap procedure can be applied to simulate from the density estimates (see Silverman 1986, p. 142-144). Draw $\boldsymbol{E}_{b c}^{1}=\left[e_{i b}^{1} e_{i c}^{1}\right](i=1, \ldots, N)$ randomly with replacement from $\boldsymbol{E}_{b c}^{R}$ where each row is drawn with equal probability. ${ }^{3}$ Then

${ }^{3}$ Note that $\boldsymbol{E}_{b c}^{1}$ is $(N \times 2)$, whereas $\boldsymbol{E}_{b c}^{R}$ is $(4 N \times 2)$. 
compute the $(N \times 2)$ matrix

$$
\boldsymbol{E}_{b c}^{2}=\overline{\boldsymbol{E}}_{b c}^{1}+\left(\boldsymbol{E}_{b c}^{1}-\overline{\boldsymbol{E}}_{b c}^{1}+h \boldsymbol{\epsilon}^{*}\right) /\left(1+h^{2}\right)^{1 / 2}
$$

where $\overline{\boldsymbol{E}}_{b c}^{1}$ is a $(N \times 2)$ matrix in which the elements of the first (second) column are the mean of the first (second) column of $\boldsymbol{E}_{b c}^{1}$ and $\boldsymbol{\epsilon}^{*}$ is the $(N \times 2)$ matrix of deviates from the bivariate normal distribution with the estimated covariance matrix $\widehat{\boldsymbol{\Sigma}}\left(\widehat{\boldsymbol{\Sigma}}^{R}\right)$ for the rows of $\boldsymbol{E}_{b c}^{2}$ that were drawn from $\left[\boldsymbol{E}_{b} \boldsymbol{E}_{c}\right]$ or $\left[2-\boldsymbol{E}_{b} 2-\boldsymbol{E}_{c}\right]$

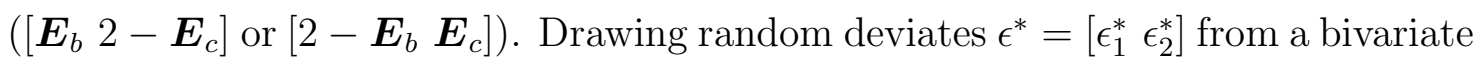
normal density with the estimated covariance matrix $\widehat{\Sigma}$ can be done using the BoxMuller method. First, draw $\epsilon_{1}$ and $\epsilon_{2}$ from the univariate normal distribution and form a $(1 \times 2)$ matrix $\epsilon=\left[\epsilon_{1} \epsilon_{2}\right]$. Then use the Cholesky decomposition to obtain an upper triangular matrix $\boldsymbol{C}$ by decomposing the matrix $\widehat{\Sigma}$. Then the matrix $\epsilon^{*}=\left[\epsilon_{1}^{*} \epsilon_{2}^{*}\right]=\epsilon \boldsymbol{C} \sim N(\mathbf{0}, \widehat{\Sigma})$. Similarly, $\epsilon^{*}=\left[\epsilon_{1}^{*} \epsilon_{2}^{*}\right]=\epsilon \boldsymbol{C}^{R} \sim N\left(\mathbf{0}, \widehat{\boldsymbol{\Sigma}}^{R}\right)$, where $\boldsymbol{C}^{R}$ is the upper triangular Cholesky decomposed matrix $\widehat{\boldsymbol{\Sigma}}^{R}$. Matrix $\boldsymbol{E}_{b c}^{*}=\left[e_{i b}^{*} e_{i c}^{*}\right]$ $(i=1, \ldots, N)$ contains simulated efficiency scores that are set as follows:

$$
e_{i j}^{*}= \begin{cases}e_{i j}^{2}, & \text { if } e_{i j}^{2} \leq 1, i=1, \ldots, N, j=b, c \\ 2-e_{i j}^{2}, & \text { otherwise }\end{cases}
$$

where $e_{i j}^{2}$ are the elements of $\boldsymbol{E}_{b c}^{2}$. The bootstrap samples in the base, $\left(S_{b}^{*}\right)$, and current, $\left(S_{c}^{*}\right)$, time periods can then be constructed as

$$
S_{b}^{*}=\left\langle Y_{i b}^{*}=Y_{i b} \frac{\widehat{e}_{i b}}{e_{i b}^{*}}, \hat{L}_{i b}^{*}=\hat{L}_{i b}, K_{i b}^{*}=K_{i b}\right\rangle_{i=1}^{N}
$$

and

$$
S_{c}^{*}=\left\langle Y_{i c}^{*}=Y_{i c} \frac{\widehat{e}_{i c}}{e_{i c}^{*}}, \hat{L}_{i c}^{*}=\hat{L}_{i c}, K_{i c}^{*}=K_{i c}\right\rangle_{i=1}^{N}
$$

The steps of generating the bootstrap samples are summarized as follows: 
1. Sample uniformly with replacement a vector $i i$ of the size $N$ from the integers $1: 4 N$.

2. Define $\boldsymbol{E}_{b c}^{1}$, the rows of which are $i$ th rows of $\boldsymbol{E}_{b c}^{R}$. Calculate $\overline{\boldsymbol{E}}_{b c}^{1}$.

3. Draw the $(N \times 2)$ matrix $\boldsymbol{\epsilon}=\left[\boldsymbol{\epsilon}_{1} \boldsymbol{\epsilon}_{2}\right]$ randomly from a standard normal density. Obtain the $(N \times 2)$ matrix $\epsilon^{*}$ as follows:

$$
\epsilon^{*}=\left\{\begin{array}{ll}
\epsilon C, & \text { for } i i \leq 2 N \\
\epsilon C^{R}, & \text { otherwise }
\end{array} .\right.
$$

4. Calculate matrix $\boldsymbol{E}_{b c}^{2}$ using Eq. (17), where $h=N^{-1 / 6}$.

5. Calculate matrix $\boldsymbol{E}_{b c}^{*}$ using Eq. (18).

6. Construct bootstrap samples $S_{b}^{*}$ and $S_{c}^{*}$ using Eq. (19) and (20).

For the given bootstrap samples construct the technologies:

$$
\mathcal{T}_{t}^{*}=\left\{\begin{array}{c}
\left\langle Y_{t}^{*}, \hat{L}_{t}^{*}, K_{t}^{*}\right\rangle \in \Re_{+}^{3} \mid Y_{t}^{*} \leq \sum_{i} z_{i}^{*} Y_{i t}^{*}, \hat{L}_{t}^{*} \geq \sum_{i} z_{i}^{*} \hat{L}_{i t}^{*}, \\
K_{t}^{*} \geq \sum_{i} z_{i}^{*} K_{i t}^{*}, z_{i}^{*} \geq 0 \forall i
\end{array}\right\}, t=b, c .
$$

Compute the potential outputs per effective units of labor that appear in Eq. (7) and (8) using the bootstrap base- and current-period technologies defined in Eq. (22) and then calculate the bootstrap components of the decomposition in Eq. (9). Apply the procedure above $B$ times ( $B$ should be large in practice) to obtain $B$ bootstrap components, $\widehat{E F F}{ }^{*}, T \widehat{E C} H^{*}, \widehat{K A C} C^{*}$, and $H \widehat{A C} C^{*}$.

\subsubsection{Confidence intervals}

Let $Z_{i}$ denote component $E F F_{i}, \widehat{Z}_{i}$ denote $\widehat{E F F}_{i}$ and $\widehat{Z}_{i}^{*}$ denote $\widehat{E F F}_{i}^{*}$ for a country $i, i=1, \ldots, N$. For an unknown distribution of $\left(\widehat{Z}_{i}-Z_{i}\right)$, construction of 
the $(1-\alpha)$-percent confidence interval boils down to finding values $a_{i \alpha}$ and $b_{i \alpha}$ in

$$
\operatorname{Prob}\left(-b_{i \alpha} \leq \widehat{Z}_{i}-Z_{i} \leq-a_{i \alpha}\right)=1-\alpha
$$

Using $B$ bootstrap values $\widehat{Z}_{i}^{*}$ we can find $a_{i \alpha}^{*}$ and $b_{i \alpha}^{*}$ such that the probability that the equation

$$
\operatorname{Prob}\left(-b_{i \alpha}^{*} \leq \widehat{Z}_{i}^{*}-\widehat{Z}_{i} \leq-a_{i \alpha}^{*} \mid S_{b}, S_{c}\right)=1-\alpha
$$

holds approaches one as $B \rightarrow \infty$. Since the bootstrap involves approximating the unknown distribution of $\left(\widehat{Z}_{i}-Z_{i}\right)$ by that of $\left(\widehat{Z}_{i}^{*}-\widehat{Z}_{i}\right)$ conditional on original samples $S_{b}$ and $S_{c}$, we can substitute $a_{i \alpha}$ and $b_{i \alpha}$ in Eq. (23) with $a_{i \alpha}^{*}$ and $b_{i \alpha}^{*}$ to obtain the bootstrap approximation based on the original sample as follows

$$
\operatorname{Prob}\left(-b_{i \alpha}^{*} \leq \widehat{Z}_{i}-Z_{i} \leq-a_{i \alpha}^{*} \mid S_{b}, S_{c}\right) \approx 1-\alpha
$$

This relationship allows us to construct the approximated $(1-\alpha)$-percent confidence interval as

$$
\widehat{Z}_{i}+a_{i \alpha}^{*} \leq Z_{i} \leq \widehat{Z}_{i}+b_{i \alpha}^{*}
$$

The efficiency change for country $i$ is said to be statistically significant (i.e., significantly different from zero) if $Z_{i}$ is statistically different from one or when the confidence interval in Eq. (26) does not include one. The statistical inference with respect to the remaining components of the decomposition in Eq. (9) for country $i$ is made by subsequently letting $Z_{i}$ denote $T E C H_{i}, K A C C_{i}$, or $H A C C_{i}$ and looking whether the respective confidence interval (26) covers unity. ${ }^{4}$

\footnotetext{
${ }^{4}$ Note that the statistical inference that we have discussed here is provided with respect to each component for each country in the decomposition (9).
} 


\section{Data}

We obtain data for 35 African countries for the period 1970 - 2007 from the Penn World Tables, Version 6.3 (see Heston et al. 2009). The number of workers is obtained as RGDPCH * POP/RGDPWOK, where RGDPCH is per capita GDP computed via the chain method, POP is the population and RGDPWOK is real GDP per worker. The measure of output is calculated as RGDPWOK multiplied by the number of workers; the resulting output is in 2005 international dollars. Real aggregate investment in 2005 international dollars is computed as RGDPL * $\mathrm{POP} * \mathrm{KI}$, where RDGPL is the real GDP computed via the Laspeyres index, and KI is the investment share of real GDP. We apply the perpetual inventory method (PIM) to the real investment series to construct the physical capital stock. More specifically, the current capital stock is the sum of the current investment and depreciated capital stock from the previous period. Following standard practice, we compute the initial capital stock, $K_{0}$, as $I_{0} /(g+\delta)$, where $I_{0}$ is the value of the investment series in the first year it is available, and $g$ is the average geometric growth rate for the investment series between the first year with available data and 1980 (Caselli and Feyrer (2007)).

For human capital, we employ the Barro and Lee (2010) education data set. The data are available every five years and we employ a linear interpolation method to obtain values in-between. ${ }^{5}$ We follow HR and adopt the Hall and Jones (1999) construction of human capital. However, instead of using the Psacharopoulos (1994) survey of wage equations to evaluate the returns to education, we use estimates reported by Psacharopoulos and Patrinos (2004) who provide a more comprehensive study of the returns to education in Africa. Table A1 of Psacharopoulos and Patrinos (2004) provides country specific returns to education for various African economies at different years. In Table 1, we show only the returns to education

\footnotetext{
${ }^{5}$ These education data are an update of widely used previous compilation of Barro and Lee (2001).
} 
that were found in case studies for African economies. To make unified and general conclusions, we average the returns for each level of education for the African countries given in their table and apply them to all countries in our sample to construct our human capital measure. Specifically, let $\epsilon_{j t}$ represents the average number of years of education of the adult population in country $j$ at time $t$ and define labor in efficiency units in country $j$ at time $t$ by

$$
\hat{L}_{j t}=H_{j t} L_{j t}=h\left(\epsilon_{j t}\right) L_{j t}=\exp ^{\phi\left(\epsilon_{j t}\right)} L_{j t}
$$

where $\phi$ is a piecewise linear function, with a zero intercept and a slope of 0.266 through the sixth year of education, 0.173 for the next six years, and 0.113 for education beyond the twelfth year (see the last line in Table 1). ${ }^{6}$ Clearly, the rate of return to education (where $\phi$ is differentiable) is

$$
\frac{\partial \ln h\left(\epsilon_{j t}\right)}{\partial \epsilon_{j t}}=\phi^{\prime}\left(\epsilon_{j t}\right)
$$

and $h(0)=1$.

\footnotetext{
${ }^{6}$ Whereas these estimates are in line with the standard finding of diminishing returns to education, an anonymous referee pointed out the work of Colclough et al. (2009) suggesting that this pattern may have changed in recent years in developing countries. In particular, the authors argue that the returns to primary education may have decreased in these countries, due to both demand and supply side factors. On the other hand, they show that the rates of return to secondary and higher education have increased in recent years in a number of developing countries. If we were to employ higher returns to education, it is likely that the results would show even larger contributions from human capital.
} 
Table 1: Returns to EDUCATION*

\begin{tabular}{|c|c|c|c|c|}
\hline \multirow[t]{2}{*}{ Country } & \multirow[t]{2}{*}{ Year of study } & \multicolumn{3}{|c|}{ Type of education } \\
\hline & & Primary & Secondary & Higher \\
\hline Botswana & 1983 & 42.0 & 41.0 & 15.0 \\
\hline Ethiopia & 1972 & 20.3 & 18.7 & 9.7 \\
\hline Ghana & 1967 & 18.0 & 13.0 & 16.5 \\
\hline Kenya & 1980 & & 10.0 & \\
\hline Lesotho & 1980 & 10.7 & 18.6 & 10.2 \\
\hline Liberia & 1983 & 41.0 & 17.0 & 8.0 \\
\hline Malawi & 1982 & 14.7 & 15.2 & 11.5 \\
\hline Morocco & 1970 & 50.5 & 10.0 & 13.0 \\
\hline Nigeria & 1966 & 23.0 & 12.8 & 17.0 \\
\hline Senegal & 1985 & 23.0 & 8.9 & \\
\hline Sierra Leone & 1971 & 20.0 & 22.0 & 9.5 \\
\hline Somalia & 1983 & 20.6 & 10.4 & 19.9 \\
\hline South Africa & 1980 & 22.1 & 17.7 & 11.8 \\
\hline Sudan & 1974 & & 8.0 & 4.0 \\
\hline Tanzania & 1982 & & 5.0 & \\
\hline Uganda & 1965 & 66.0 & 28.6 & 12.0 \\
\hline Zambia & 1983 & & & 5.7 \\
\hline Zimbabwe & 1987 & 11.2 & 47.6 & -4.3 \\
\hline The Gambia & 1997 & 33.5 & 12.1 & \\
\hline Burkina Faso & 1982 & 20.1 & 14.9 & 21.3 \\
\hline Ethiopia & 1996 & 14.9 & 14.4 & 11.9 \\
\hline Average & & 26.6 & 17.3 & 11.3 \\
\hline
\end{tabular}

* Source: Table A1 of Psacharopoulos and Patrinos (2004)

\section{4 (In)significant results}

Here we present our main results. First, we look for significance of the average estimates, both weighted and unweighted, from the decomposition. Second, we focus on the estimates for specific countries and pay attention to countries that deviate from average behavior. Third, since we believe that African countries belong to a different frontier than the rest of the world, we perform the same analysis for other otherwise homogeneous economic groups such as OECD, Latin America, and Asia for the same time period. 
The samples which we employ in our analysis are relatively small and may seem to be rather 'non-random' (which is a violation of the assumption used to prove that the bootstrap procedure is consistent). Even though we have virtually all the countries from the African continent, we mean randomness not as that of the observations, but rather in the sense of current realization resulting from potentially infinite number of possible outcomes. ${ }^{7}$

\subsection{Average estimates}

The final two lines of Table 2 list two measures of average results across the 35 economies. In particular, the row labeled "Average" is the simple arithmetic average of individual estimates whereas the "Weighted Average" weights each of the estimates by their relative 2007 output, similar to Zelenyuk (2011).

The average productivity growth in Africa over the $1970-2007$ period is $54 \%$. While this number may not seem small, it is markedly low compared to that achieved by fast growing economies. For instance, the $54 \%$ average African productivity growth is nearly four times as large for Ireland (208\%) and nearly twenty times as large for China (1120\%) over the same time frame. In annual terms, the average productivity growth in Africa was a mere $1.17 \%{ }^{8}$ Over the same time period, the average annual growth rates for OECD, Latin American, Asian, and East Asian economies are $1.90,0.56,3.21$, and $4.50 \%$, respectively. ${ }^{9}$

\footnotetext{
${ }^{7}$ We would like to thank an anonymous referee for pointing this out.

${ }^{8}$ Note that this is a crude approximation of the average productivity evolution over the entire period on a yearly basis under the assumption of constant productivity growth.

${ }^{9}$ Note that the confidence bounds cannot be provided for productivity measures since they are actual data points, not point estimates.
} 
The average $E F F, T E C H, K A C C$, and $H A C C$ components are $-38.21,1.53$, 67.35 and $60.19 \%$, respectively. ${ }^{10}$

Inefficiency has regressed African growth whereas technological change is essentially nonexistent. Moreover, ignoring statistical significance, ${ }^{11}$ these results suggest that capital deepening is the primary driver of labor productivity growth in Africa followed by human capital accumulation.

Among the four components, however, only efficiency changes and human capital accumulation are statistically significant on average. ${ }^{12}$ Thus, if we ignore statistical inference, we would falsely conclude that the physical capital accumulation is the major driving force behind productivity growth.

The weighted averages, ignoring statistical significance, show that human capital accumulation plays a larger role than physical capital accumulation. This result implies that relatively larger economies (in 2007) have benefited more from human capital accumulation. In any case, we still see that the contribution of physical capital accumulation and technology changes are statistically insignificant on average whereas efficiency losses significantly reduce growth and human capital accumulation significantly encourages growth in Africa.

\footnotetext{
${ }^{10}$ Percentages are obtained by subtracting 1 from the index and multiplying by 100 . Because of compounding, the average contributions of individual components do not, of course, sum to the average productivity change.

${ }^{11}$ We note that bootstrap techniques have been applied for inference regarding aggregate efficiencies of countries (see Henderson and Zelenyuk 2007), but not with respect to the components of decomposition.

${ }^{12}$ Delgado et al. (forthcoming) find an insignificant impact of human capital in growth regressions. Similarly, Acemoglu et al. (2014) find much lower (and sometimes insignificant) impacts of human capital accumulation on growth. Our finding may imply that the production function framework is a better way to capture the empirical impact of human capital accumulation.
} 
The positive and significant effect of human capital may capture the direct as well as the indirect beneficial impacts that this factor brings to growth. For instance, Weir and Knight (2000) presents evidence showing that educated farmers help to improve the productivity of their non-educated counterparts in rural Ethiopia. In the same way, Keller (2006) presents cross-country empirical evidence showing several benefits of education, including lowering fertility, attracting investment in physical capital and improving political rights.

The insignificance of physical capital can have several roots. For instance, it may be related to the high cost of investment in Africa. ${ }^{13}$ Artadi and Sala-i Martin (2003) argue that the relative prices of investment (to consumption) goods are about 50 percentage points larger in Africa than in East Asian and OECD countries (120 versus $70 \%$ ). As such, the value of the capital stock constructed by the researcher, from observed investment data, will overstate the productive capital stock. In line with this reasoning, Artadi and Sala-i Martin (2003) claim that African growth would have benefited from an additional yearly 0.44 percentage point if its relative price of investment goods were the same as those of the OECD countries. In the same way, the value of the public capital stock in developing countries does not necessarily reflect its public investment cumulated at cost (Pritchett 2000). Further, if government investment spending has created little useful capital, its contribution to productivity growth will likely be insignificant. This is certainty the case when public investment is more motivated by rent-seeking and political considerations (Keefer and Knack 2007). The lack of basic education that characterized many African countries in the 1960s and 1980s (for the indirect effects of education in contributing to less political instability, to democratization, to reduced fertility

\footnotetext{
${ }^{13}$ Much of African investment goods are imported from abroad such that their high value presumably reflects high taxation and transportation cost as well as the monopoly power of the few domestic importing firms.
} 
rates and slower population growth) could be another potential explanation of the insignificant role of physical capital accumulation.

Finally, public investment will create little productive capital if the government does not plan (well) how this spending is financed. For instance, during the commodity booms of the 1970s, 1980s and 1990s many African countries initiated large scale investment projects of long-term maturities, expecting that the booms will last forever. When the booms ended some of these ongoing projects were simply suspended and other were financed with foreign borrowing which later caused the sovereign debt crisis of the 1980s (Collier and Gunning 2008).

In line with the above explanations, our estimates of efficiency changes may capture the inefficiency of African economies in converting their investment into productive capital stock (Pritchett 2000).

Policy choices also mater for the quality of private investment. For instance, in an environment where the government levies excessive taxes to finance favour groups, economic agents will allocate a higher share of resources to low productive non taxable activities (Adam and O'Connell 1999, Bates 1983, Collier and Gunning 1999a). This bad redistributive norm is likely to occur more in autocratic regimes compared to democratic ones. It will generate more unproductive physical capital, but also an inefficient resource allocation. The majority of African countries have been characterized by autocratic regimes from 1973-1994 (Ndulu and O'Connell 1999). In the same way, the development strategy followed by the majority of African countries in the 1970s and 1980s that relies on nationalization policies and excessive spending may explain the weak contributions of physical capital and technology as well as the loss in efficiency in these economies. Civil wars and armed conflicts that were common in Africa in the 1980s and 1990s are also other potential explanations of these outcomes (Collier 1999). 
Finally, the characterization of the African inefficiency may be related to some persistent factors. These include, but are not limited to, genetic diversity recently (Ashraf and Galor (2013)), low soil quality due to tropical climates (Bloom and Sachs 1998), the slave trade (Nunn 2008), and kinship sharing that discourages effort (Platteau 2009) and encourages a misallocation of resources (Baland et al. 2011).

\subsection{Individual estimates}

Many of the individual results reported in Table 2 mimic the averages. First, most $H A C C$ components are positive and significant. Second, virtually all technology components are near zero and none are statistically significant. In particular, we find very small changes in technology across the countries and none of them are significant. In fact, only 11 countries have components (numerically) different from zero. This result is perhaps expected as HR and others have shown that there is little to no technological improvement for Africa. The difference here is that we are able to show this with statistical evidence.

Third, the majority of efficiency components are negative and statistically significant. Only, Malawi and Mauritius display positive and significant efficiency components. Fourth, although most $K A C C$ are insignificant, we find several (8/35) which are positive and significant: Botswana, Egypt, Lesotho, Liberia, Mali, Mauritius, Sudan, and Swaziland. Combining with significant results on efficiency, these amount to a total of nine (country) observations, which differ from the average results, that we will now discuss. In doing so, we rely on the existing literature on these countries where we relate our results to those reported in the literature. That being said, a complete country level analysis (for any given country) is beyond the scope of this paper. 


\subsubsection{Mauritius}

Among the nine observations, Mauritius distinguishes itself from the rest for having both positive and statistically significant physical capital and efficiency components (see columns 3 and 5 of Table 2). This finding is consistent with the widely held view that Mauritius is a success story (Sachs et al. 1995, Sachs and Warner 1997, Subramanian and Roy 2001, Subramanian 2009, Frankel 2010).

Like most African resource poor countries Mauritius, was a commodity dependent economy in the 1960s and sugar was the main driver of real activity in the country. This single good based economy made the country vulnerable to trade and rainfall shocks. During the same period Mauritius faced other challenges including rapid population growth, huge unemployment, and political and ethnic conflicts. These weak initial conditions led some economists to ponder whether or not that country would fail to develop (Meade 1961). In 1963 Mauritius adopted the popular industrialization strategy based on Import Substitution Industrialization (ISI). One key difference was that the private sector remained the main actor of the Mauritius production sector whereas the implementation of ISI in other African countries was supported by a large amount of nationalizations. However, this first attempt to diversify the Mauritius economy did not bring impressive growth certainly in part due to instabilities related to political and ethnic conflicts that were ongoing (Nath and Madhoo 2008). The real success of Mauritius occurred after it gained independence from the British in 1968. Following this event, the country developed political and market institutions that facilitated sustained growth (Subramanian 2009, Frankel 2010). The political institutions involved a parliamentarian system with an open competition in elections and a voice for minority ethnic groups, no ruling elite and power sharing in ministry cabinets, and a limited role for the army. The market institutions included private property rights and institutions that encouraged con- 
tracts. The results reported in the third column of Table 2 capture these effects where we find that Mauritius has the largest efficiency component.

In addition, Mauritius made a number of important economic policy choices. First, the government established an Export Processing Zone (EPZ) that has been the driver for manufacturing export and FDI which encouraged technology transfer and knowledge spill-over. Second, investment in human and physical capital as well as prudent exchange rate policies ensured that the manufacturing sector remains competitive (Nath and Madhoo 2008). Third, the successive governments have often implemented appropriate adjustment and stabilization policies as well as good decisions in international trade agreements. For instance, whereas the majority of African countries had difficulties in adjusting to the commodity price shocks of the 1970s and 1980s, Mauritius made successful stabilization policies and recovered fast from these shocks (Gulhati and Nallari 1990). In the same way, Mauritius accepted in the early 1970s a trade deal which involved a higher export quota of sugar to the EU but at a lower EU domestic price whereas other developing countries signed an agreement for selling at the then higher world sugar price but with a limited quota (Subramanian 2009). Afterwards, the choice of Mauritius proved to be better as the world commodity prices collapsed but the EU domestic price increased due to subsidized policies. All these policies probably contribute to explain the positive role of the four components to labour productivity growth. However, technology change is not statistically significant (see the entry 19 in Table 2). We will return to this in Section 4.3.

\subsubsection{Cote d'Ivoire}

The Mauritius growth promoting policy choices and institutional framework contrast with those of poor performers in Table 2. Cote d'Ivoire is similar to Mauritius in that it does not have many natural resources and has costal access (Collier and 
O'Connell 2008), but also Cote d'Ivoire was considered as a successful African story in the 1960s and 1970s (IBRD 1970, Den Tuinder 1978, Hecht 1983). In particular, Cote d'Ivoire had real growth of about 8\% a year from 1960-1970 (Ridler 1985). This growth record was unusual in Sub-Saharan Africa at that moment and this led some observers to qualify this performance as a miracle (the 'ivoirian miracle') (IBRD 1970).

Three types of factors facilitated the success of Cote d'Ivoire from 1960-1970. The first relates to its political stability whereas neighboring countries have been plagued with several coups d'état. This fact helped to attract FDI and foreign skilled labour that developed the manufacturing sector (Den Tuinder 1978). FDI have also been encouraged by several tax advantages and import duties.

Second, the government implemented an outward development strategy which was essentially based on the export of coffee and cocoa. For this purpose, a number of policies were used to encourage the supply of these crops (Hecht 1983, Ridler 1985, Lee 1980, Ridler 1988): price support and payment of bonuses to farmers; import of cheap labour from the north of the country and neighboring countries (Burkina Faso, Mali and Guinea); open rule and secured land tenure to immigrant farmers; and a marketing and price stabilization system operated by the Caisse Nationale de Stabilisation et de Soutien des Prix Agricoles (CSSPPA). However, CSSPPA also served for the extraction of rents which were used to invest in physical and human capital (Azam 1993). Third, the prices of cocoa and coffee which were on a positive trend before 1975, experienced a boom from 1976-1978, following Brazil's frost in July 1975.

Following this boom the government undertook excessive investment programs in infrastructure and public enterprises. Similar unsustainable government spending occurred in many African countries during the commodity booms of the 1970s, 1980s and 1990s (Collier and Gunning 2008): Burundi (1972-1982); Cameroon 
(1970s, 1980s and 1990s); Congo (1978-1991); Guinea (1973-1984); Niger (19741985); Nigeria (1970-1987); and Togo (1974-1974).

When the boom reversed in 1979 Cote d'Ivoire continued these programs with external borrowing. However, many of these projects turned out to be unproductive or took a long time to implement (Lee 1980, Davis 1983). One often mentioned explanation of this mismanagement is the political system of Cote d'Ivoire which was characterized by a single elite ruler, president Houphouët-Boigny, who settled a one-party system after the independence in 1960 and extracted state resources to finance urban clientelism in order to keep his power. There were little controls over government budget (Crook 1989, Campbell 2000, Hecht 1983). As such, debt services climbed and a debt crisis emerged in 1980. Meanwhile Cote d'Ivoire faced other imbalances (e.g. overvaluation of the currency, balance of payment crisis) and all these contributed to a growth collapsed in the 1980s. To solve these problems a number adjustment programs were initiated from 1981-1993, but these were not very successful (Azam and Morrisson 1994, Berthelemy and Bourguignon 1996, Demery 1994). Cote d'Ivoire only renewed with balanced growth after an unprecedented devaluation in 1994. However, this new growth process was interrupted by political tensions that started in 1998. The tension led to a coup d'état in 1999 and armed conflicts from 2000-2012 that severely discouraged factor accumulation and induced a misallocation of resources. All these events certainly explain why physical capital is not significant and also the efficiency loss in Cote d'Ivoire as reported in Table 2.

\subsubsection{Malawi}

Another country that fares differently than the average is Malawi, for displaying a positive efficiency component. Malawi is a small landlocked resource poor country. In the 1960s and 1970s Malawi had a stable and better growth performance compared to other African landlocked counterparts such as Burundi and Rwanda 
but also its neighbors Mozambique, Tanzania and Zambia. This good performance was the result of an outward development strategy based on tobacco, a cash crop, and light manufacturing as in Cote d'Ivoire (World Bank 1981). Contrary to Cote d'Ivoire, however, Malawi avoided a number of syndromes: state break-down, excessive government intervention and overspending (Chipeta and Mkandawire 2008). In the 1980s and early 1990s Malawi faced a number of adverse shocks which regressed growth. These included a severe drought, oil price shocks, a pronounced reduction in the number of Malawian working in mining in South Africa (which severely reduced remittances), and an increase in transaction costs through Mozambique (which has access to the sea), but experienced political problems in the period. From the mid-1990s, Malawi renewed with a stable growth path following successful structural and adjustment programs supported by the IMF and other donors but also a number of reforms that strengthened domestic political institutions (IMF 2001). This achievement could well reflect our finding of the positive and significant contribution of the efficiency component in Malawi (see column 3 of Table 2). This growth performance improved further since the early 2000 following the successful implementation of a number of poverty reduction programs. In particular, Malawi is currently a net food exporter in contrast to its earlier years of food insecurity. This performance contrasts with other landlocked countries such as Niger, Burundi, and Rwanda that performed poorly. One thing that these countries have in common is the recurrent occurrence of civil wars and armed conflicts that have severely constrained their economic development (Collier and O'Connell 2008).

\subsubsection{Botswana}

Among the remaining seven individuals that differ from the average, Botswana displays the largest labour productivity growth and has also been cited as a successful story (Acemoglu et al. 2002). Botswana is a resource-rich country, a feature that 
increases the likelihood of political instability and arms conflicts as they have occurred in many cases in Africa - including Sierra Leone and Zambia (Collier and O'Connell 2008). However, Botswana avoided these syndromes thanks to good political institutions that enhance power sharing and political accountability, secure property rights and encourage contracts (Maipose and Matsheka 2008). Moreover, Botswana is well known for its Budget Sustainable Index (BSI) which imposes discipline on government budget management. These factors probably explain why physical capital has contributed to growth in Botswana.

\subsubsection{Mali}

The remaining countries with significant physical capital are: Mali, Liberia, Sudan, Egypt, Lesotho, Sudan, and Swaziland. Apart from Egypt, these countries were much poorer in the 1960s and 1970s, with very small levels of capital. Moreover, they have experienced either armed conflicts, civil wars and/or political instability. When their political situation improved, their governance improved as well, which probably helped to attract some FDI in their mining sectors.

Whereas political instability and excessive government intervention and mismanagement retarded growth in Mali before from 1960-1980, the country experienced stable growth from 1994-2007 thanks to successful structural and political reforms. Moreover, Mali discovered important gold reserves in the 1990s which helped to attract FDI (Coulibaly 2008). In the same way, Sudan has performed poorly in the 1970s and 1980s because of civil wars and bad governance. In the mid 1990s, the situation improved and the country also discovered large oil and natural gas which then attracted FDI that contributed to the domestic capital stock. 


\subsubsection{Liberia}

The experience of Liberia is, however, different. Liberia experienced a huge economy collapsed following a series of armed conflicts from 1979-2003. To rebuild the country donors massively contributed to several projects to rebuild the capital stock and invest in human capital as well as providing technical assistance to reshape the institutions. The improvement of the political climate also encouraged FDI in the mining sector (Werker and Beganovic 2011). These factors have thus helped to rebuild the capital stock (per worker) which was estimated to be much higher in 2007 compared to its level in 1970 (2015.15 versus 647 although it reached a peak of 7531.75 in 1983). It is probably this trend that our result is capturing.

\subsubsection{Lesotho and Mozambique}

Finally, it is also interesting to see losers in terms of human capital accumulation. Only two countries have insignificant $H A C C$ terms. Specifically, Lesotho and Mozambique have small positive, but insignificant components (see the last column of Table 2). This result may reflect the damaging effect that HIV has had on human capital development in these countries (Channing 2006). Note, however, that the result for Mozambique may primarily reflect the huge loss in human capital following the independence war (1964-1974) as well as the civil war (1976-1992) that devastated the country from 1964-1992 (de Sousa and Sulemane 2008). In particular, the literature reports strong negative long-term effects of these wars on school enrollments in Mozambique (e.g. Domingues 2011, UNESCO 2010). Civil wars in other African countries certainty also impacted negatively on their school enrollments. However, the average years of schooling data displays an unusual dynamic for Mozambique, stagnating around 1 from 1965-1970, decreasing to 0.95 in 1975 and standing at 1.81 in 2010 . The data on school enrollment shows a strong positive trend in other countries that experienced wars in the region. Moreover, the 
1-1.81 Mozambican average years of schooling increase from 1970-2010 is markedly lower than the 1.05-3.94 average gain in other countries (Cote d'Ivoire, 1.26-4.60; Democratic Republic of the Congo, 1.16-3.26; Liberia, 1.14-5.11; Rwanda, 1.16-3.96; Sierra Leone, 0.87-3.42; Sudan, 0.73-3.3) that had war and from armed conflicts in the region. It is probably these different dynamics in years of schooling that our estimates are capturing. The difference in years of schooling between Mozambique and those countries are likely due to the differences in intensity and the duration of wars but also to different post-conflict policies and institutional environments. ${ }^{14}$

\subsection{Sub-Period Analysis}

Because the long-term results presented in Table 2 and discussed above may belie various important growth patterns over almost 40 years, we have carried out the above calculations for each ten-year interval in our sample. Table 3 shows the average results for 4 time intervals: 1970-1979, 1980-1989, 1990-1999, and $2000-2007 .^{15}$

Those familiar with the African growth experience will immediately recognize the inverted U-shape that features its historical growth (Berthelemy and Söderling 2001, Ndulu and O'Connell 1999, 2009): the highest productivity growth in the (1960s and) 1970s, the slowed and collapsed growth of the 1980s and (early) 1990s, the recovery of the late 1990s, and the steady growth of the 2000s.

Our quadripartite decomposition shows that human capital accumulation is the only positive and significant contributor to the average productivity growth through

\footnotetext{
${ }^{14}$ See Guariso and Verpoorten (2014) for a recent survey on different channels through which armed conflicts impact education.

${ }^{15}$ Note that in each of the these time intervals, the assumption that technological regress is precluded has been maintained; for example in the 1990-1999 analysis, the countries have an access to technologies defined by observations back to the 1970 s.
} 
the sub-periods. In each of the time intervals, except for the 1970s, its value has been the largest positive and absolute terms. The remaining three factors have been either detrimental or non existent (see Table 3). For instance, in all periods, except for the 2000s, deterioration in efficiency has been statistically significant, precluding productivity from growing. The 1970s appear to have set the technological bar for the African countries for decades to come. ${ }^{16}$ Yet, the contribution from technological change at the beginning is rather small in magnitude and is it not statistically significant. However, one needs to be careful here. Those who visit Africa see the speed and the scale with which new technologies such as computers and cell phones reach the continent. Data limitation (in the time dimension) may be the reason why our analysis is not able to capture these effects. We plan to investigate this point in our future research.

Note that the results (in Tables 2 and 3) suggesting the absence of technological progress may also capture the failed diffusion of technological advances from rich countries to Africa. Several factors are possible. ${ }^{17}$ First, the new knowledge and technologies found in rich countries do not simply disseminate widely in Africa because of a lack of basic infrastructure such as electronic (or other) access to scientific (international) journals. Second, even if African countries are aware of new technologies, they may not be able to use them because the new technology may require a combination of human and physical capital that are not available in these countries. In particular, because firms in the region rarely perform even basic research and applied research and development, they will find it difficult to use capital intensive technologies. Limited access to high power electricity that characterizes many African countries is another constraint for capital intensive technologies (e.g.,

\footnotetext{
${ }^{16}$ Note the averages for $1970-1979$ and $1970-2007$ are roughly identical.

${ }^{17}$ We would like to thank a referee for drawing our attention to this point. See also Weil (2008) for a discussion on the possible explanations of a lack of technology transfer from rich to poor countries.
} 
magnetic levitation trains). Third and finally, African countries may not be able to use technologies developed in rich countries because they lack tacit knowledge.

The simple average of physical capital accumulation is statistically significant only in the 1970s. When we, however, consider a weighted average (see Zelenyuk 2011), the component is smaller and becomes insignificant. This implies that the relatively smaller economies have benefited more from capital deepening and that this component has been insignificant for the relatively larger economies. The 1970s appear to be the only time interval where capital accumulation component shows any sign of significance, which has also driven the overall long-term results. The influence of the accumulation of capital has picked up in the 2000s, but it is still insignificant.

The poor African growth performance of the 1980s and early-1990s thus coincided with slow capital accumulation, efficiency losses and stagnant technological progress. This finding is consistent with studies that employ standard growth accounting (Berthelemy and Söderling 2001, Ndulu and O'Connell 1999, 2009). However, we show that only the result related to efficiency is significant (technological change is insignificant). In the same way, the recovery and steady African growth of the mid-1990s and 2000s coincided with improvement in efficiency and capital accumulation.

These decade-wise results confirm the long-term tendencies that we have unveiled in the previous sections. The rather modest productivity growth has been largely driven by human capital accumulation, whereas the inability to catch-up with technological change was the major impediment to productivity growth. The contribution of the physical capital accumulation has proved to be a statistically insignificant factor. 


\subsection{Other Regions of the World}

Our analysis has shown that capital accumulation was not on average a significant force behind the productivity growth in Africa. As a robustness check, we perform the same analysis for other groups that are homogeneous in either their geographical proximity or economic relation. Table 4 presents the simple and weighted average for the same time period, 1970-2007, for OECD, Latin American, Asian and East Asian economies.

All the components of the decomposition are statistically significant for OECD economies. Capital deepening is easily the largest determinant of the productivity growth, that amounts to approximately $2 \%$ in annual terms. We further note that OECD is the only group whose productivity has profited from technological changes.

The inability to catch up was also a statistically significant hindrance to productivity growth for the Latin American countries. They have significantly benefited from human capital accumulation. Similar to the 1970s analysis of the African economies, physical capital accumulation has significantly helped Latin American economies grow. However, once we weight it by the size of the economy, the capital accumulation component gets smaller and is statistically insignificant.

Over 1970-2007, the pace of productivity growth of the Asian and especially the East Asian economies has been the largest in the world. Whether we consider a simple or weighted average, physical capital accumulation is (by the factor of at least ten) the largest driver of such grand growth. Asian countries have also statistically significantly benefited from both efficiency change and human capital accumulation.

In summary, the results show that physical capital accumulation is a large and significant contributor to productivity growth elsewhere, but not in Africa. 


\section{Conclusion}

Studying growth patterns and determinants of African economies is essential for understanding what can be done to reduce the gap between the performance of the continent and the rest of the world. Using bootstrap methods originally designed for Malmquist indices, we introduce statistical inference into the quadripartite decomposition of labor productivity growth developed by HR to analyze the components of growth in Africa. The results identify human capital accumulation as a major and the only positive and significant (in a statistical sense) driving force behind labor productivity growth in Africa. The study also shows that productivity growth is significantly hampered by efficiency losses. Technological change is nonexistent in the sample. Finally, and most importantly, ignoring statistical inference would lead us to falsely conclude that physical capital accumulation is a major economic engine in Africa when it is not. Further analysis shows that physical capital accumulation is an important growth factor, and for Asian countries, is the primary contributor to productivity growth. 


\section{References}

Acemoglu, D.: 2009, Introduction to Modern Economic Growth, Princeton.

Acemoglu, D., Gallego, F. A. and Robinson, J. A.: 2014, Institutions, human capital and development, Working Paper 19933, National Bureau of Economic Research.

Acemoglu, D., Johnson, S. and Robinson, J. A.: 2001, The colonial origins of comparative development: An empirical investigation, American Economic Review 91(5), 1369-1401.

Acemoglu, D., Johnson, S. and Robinson, J. A.: 2002, An african success story: Botswana, CEPR Discussion Papers 3219, C.E.P.R. Discussion Papers.

Acemoglu, D., Johnson, S., Robinson, J., Fergusson, L., Querubn, P. and For, B. W.: 2005, Institutions as the fundamental cause of long-run growth, In Handbook of Economic Growth, ed. Philippe Aghion and Steven Durlauf, Elsevier, pp. 385-472.

Adam, C. S. and O'Connell, S. A.: 1999, Aid, taxation and development in subsaharan africa, Economics and Politics 11(3), 225-253.

Artadi, E. and Sala-i Martin, X.: 2003, The economic tragedy of the XXth century: Growth in africa, NBER Working Papers 9865, National Bureau of Economic Research.

Ashraf, Q. and Galor, O.: 2013, The "out of Africa" hypothesis, human genetic diversity, and comparative economic development, American Economic Review 103(1), 1-46.

Azam, J.-P.: 1993, The 'cote d'ivoire' model of endogenous growth, European Economic Review 37(2-3), 566-576.

Azam, J.-P. and Morrisson, C.: 1994, La Faisabilit politique de l'ajustement en Cte d'Ivoire et au Maroc, OCDE.

Badunenko, O., Henderson, D. J. and Zelenyuk, V.: 2008, Technological Change and Transition: Relative Contributions to Worldwide Growth During the 1990s, Oxford Bulletin of Economics and Statistics 70(4), 461-492.

Badunenko, O., Henderson, D. and Russell, R.: 2013, Polarization of the worldwide distribution of productivity, Journal of Productivity Analysis 40(2), 153-171. 
Badunenko, O. and Romero-Ávila, D.: 2013, Financial Development And The Sources Of Growth And Convergence, International Economic Review 54(2), 629663.

Baland, J.-M., Guirkinger, C. and Mali, C.: 2011, Pretending to be poor: borrowing to escape forced solidarity in Cameroon, Economic Development and Cultural Change 60(1), 1-16.

Barro, R. J. and Lee, J.-W.: 2001, International data on educational attainment: Updates and implications, Oxford Economic Papers 53(3), 541-563.

Barro, R. J. and Lee, J.-W.: 2010, A new data set of educational attainment in the world, Working Paper 15902, National Bureau of Economic Research.

Bates, R. H.: 1983, Governments and agricultural markets in africa, The Role of Markets in the World Food Economy, Johnson, D. Gale and G. Edward Schuh, eds., Boulder CO: Westview Press.

Berthelemy, J.-C. and Bourguignon, F.: 1996, Growth and crisis in Cte d'Ivoire, World Bank Publications.

Berthelemy, J.-C. and Söderling, L.: 2001, The role of the capital accumulation, adjustment and structural change for economic take-off: Empirical evidence from African growth episodes, World Development 29, 323-343.

Bloom, D. E. and Sachs, J. D.: 1998, Geography, demography, and economic growth in Africa, Brookings Papers on Economic Activity 29(2), 207-296.

Bosworth, B. P. and Collins, S. M.: 2003, The empirics of growth: An update, Brookings Papers on Economic Activity 34(2), 113-206.

Campbell, B.: 2000, Rinvention du politique en cte d"ivoire et responsabilit des bailleurs de fonds multilatraux, Politique africaine 78, 142-156.

Caselli, F. and Feyrer, J.: 2007, The marginal product of capital, Quarterly Journal of Economics 122(2), 535-568.

Channing, A.: 2006, HIV/AIDS, human capital, and economic growth prospects for Mozambique, Journal of Policy Modeling 28(5), 477-489.

Chipeta, C. and Mkandawire, M.: 2008, Man-made opportunities and growth in malawi, The Political Economy of Economic Growth in Africa, 1960-2000, Cambridge University Press. 
Colclough, C., Kingdon, G. and Patrinos, H. A.: 2009, The Pattern of Returns to Education and its Implications, Research Consortium on Educational Outcomes \& Poverty, Policy Brief Number 4.

Collier, P.: 1999, On the economic consequences of civil war, Oxford Economic Paper 51(1), 168-183.

Collier, P. and Gunning, J. W.: 1999a, Explaining african economic performance, Journal of Economic Literature 37(1), 64-111.

Collier, P. and Gunning, J. W.: 1999b, Why has Africa grown so slowly?, Journal of Economic Perspectives 13(3), 3-22.

Collier, P. and Gunning, J. W.: 2008, Sacrificing the future: intertemporal strategies and their implications for growth, in B. J. Ndulu, S. A. O'Connell, R. H. Bates, P. Collier and C. C. Soludo (eds), The Political Economy of Economic Growth in Africa, 1960-2000, Vol. 1 of Cambridge Books, Cambridge University Press.

Collier, P. and Hoeffler, A.: 2004, Greed and grievance in civil war, Oxford Economic Papers 56(4), 563-595.

Collier, P. and O'Connell, S. A.: 2008, Opportunities and choices, in B. J. Ndulu, S. A. O'Connell, R. H. Bates, P. Collier and C. C. Soludo (eds), The Political Economy of Economic Growth in Africa, 1960-2000, Vol. 1 of Cambridge Books, Cambridge University Press.

Coulibaly, Massa et Diarra, A.: 2008, Mali : du tout etat la croissance invisible, in B. J. Ndulu, S. A. O'Connell, R. H. Bates, P. Collier and C. C. Soludo (eds), The Political Economy of Economic Growth in Africa, 1960-2000, Vol. 2 of Cambridge Books, Cambridge University Press.

Crook, R. C.: 1989, Patrimonialism, administrative effectiveness and economic development in cote d'icoire, African Affairs 88(351), 205-228.

Davis, J. M.: 1983, The economic effects of windfall gains in export earnings, 19751978, World Development 11(2), 119-139.

de Sousa, C. A. and Sulemane, J.: 2008, Mozambiques growth performance, 19601997, The Political Economy of Economic Growth in Africa, 1960-2000, Cambridge University Press. 
Delgado, M., Henderson, D. J. and Parmeter, C. F.: forthcoming, Does education matter for economic growth?, Oxford Bulletin of Economics and Statistics (doi: 10.1111/obes.12025).

Demery, L.: 1994, Cte-divoire: Fettered adjustment, in I. H. et Rashid Faruqee (ed.), Adjustment in Africa: Lessons from Country Case Studies, World Bank, Washington.

Den Tuinder, B. A.: 1978, Ivory Coast, Challenge of Success., Johns Hopkins University Press.

Domingues, P.: 2011, Civil War Exposure And School Enrollment: Evidence From The Mozambican Civil War, NEPS Working Papers 1/2011, Network of European Peace Scientists.

URL: http: //ideas. repec. org/p/ris/nepswp/2011_001. html

Easterly, W. and Levine, R.: 1997, Africa's growth tragedy: Policies and ethnic divisions, The Quarterly Journal of Economics 112(4), 1203-1250.

Färe, R., Grosskopf, S., Norris, M. and Zhang, Z.: 1994, Productivity growth, technical progress and efficiency change in industralized countries, American Economic Review 84, 66-83.

Farrell, M. J.: 1957, The measurement of productive efficiency, Journal of the Royal Statistical Society. Series A (General) 120(3), 253-290.

Frankel, J.: 2010, Mauritius: African success story, Working Paper Series rwp10036, Harvard University, John F. Kennedy School of Government.

Gallup, J., Sachs, J. and Mellinger, A.: 1999, Geography and economic development, in S. J. Pleskovic B (ed.), Annual Conference on Development Economics, Washington, DC: World Bank.

Grosskopf, S. and Self, S.: 2006, Factor accumulation or TFP? A reassessment of growth in Southeast Asia, Pacific Economic Review 11(1), 39-58.

Guariso, A. and Verpoorten, M.: 2014, Armed conflict and schooling in Rwanda: Digging deeper, HiCN Working Papers 166, Households in Conflict Network.

URL: http://ideas.repec.org/p/hic/wpaper/166.html

Gulhati, R. and Nallari, R.: 1990, Successful stabilization and recovery in mauritius., Technical report, EDI development policy case series. Analytical case studies, no. 5, World Bank, Washington DC. 
Hall, R. E. and Jones, C. I.: 1999, Why do some countries produce so much more output per worker than others?, Quarterly Journal of Economics 114(1), 83-116.

Hecht, R. M.: 1983, The ivory coast economic miracle: What benefits for peasant farmers?, The Journal of Modern African Studies 21, 25-53.

Henderson, D. J. and Parmeter, C. F.: 2014, Applied Nonparametric Econometrics, Cambridge University Press.

Henderson, D. J. and Russell, R. R.: 2005, Human capital and convergence: A production-frontier approach, International Economic Review 46(4), 1167-1205.

Henderson, D. J. and Zelenyuk, V.: 2007, Testing for (efficiency) catching-up, Southern Economic Journal 73(4), 1003-1019.

Heston, A., Summers, R. and Aten, B.: 2009, Penn World Table Version 6.2, Center for International Comparisons of Production, Income and Prices at the University of Pennsylvania, Philadelphia.

Hoeffler, A. E.: 2002, The augmented Solow model and the African growth debate, Oxford Bulletin of Economics and Statistics 64(2), 135-158.

IBRD: 1970, Economic growth and Prospects of the Ivory Coast, International Bank for Reconstruction and Development, International Development Association.

IMF: 2001, Malawi: Selected issues and statistical appendix, Technical report, International Monetary Fund.

Jeon, B. M. and Sickles, R. C.: 2004, The role of environmental factors in growth accounting: a nonparametric analysis, Journal of Applied Econometrics 19(5), 567591.

Keefer, P. and Knack, S.: 2007, Boondoggles, rent-seeking, and political checks and balances: Public investment under unaccountable governments, The Review of Economics and Statistics 89(3), 566-572.

Keller, K. R. I.: 2006, investment in primary secondary and higher education and the effects on economic growth, Contemporary Economic Policy 24(1), 18-34.

Klenow, P. J. and Bils, M.: 2000, Does Schooling Cause Growth?, American Economic Review 90(5), 1160-1183. 
Kneip, A., Park, B. U. and Simar, L.: 1998, A note on the convergence of nonparametric DEA estimators for production efficiency scores, Econometric Theory 14, 783-793.

Kneip, A., Simar, L. and Wilson, P. W.: 2008, Asymptotics for dea estimators in non-parametric frontier models, Econometric Theory 24, 1663-1697.

Kumar, S. and Russell, R. R.: 2002, Technological change, technological catchup, and capital deepening: Relative contributions to growth and convergence, American Economic Review 92, 527-548.

Lee, E.: 1980, Export-led rural development: The ivory coast, Development and Change 11(4), 607-642.

Lucas, R. J.: 1988, On the mechanics of economic development, Journal of Monetary Economics 22(1), 3-42.

Maipose, G. S. and Matsheka, T. C.: 2008, The indigenous developement state and growth in botswana, The Political Economy of Economic Growth in Africa, 1960-2000, Cambridge University Press.

Mankiw, N. G., Romer, D. and Weil, D. N.: 1992, A Contribution to the Empirics of Economic Growth, The Quarterly Journal of Economics 107(2), 407-37.

Masters, W. A. and McMillan, M. S.: 2001, Climate and scale in economic growth, Journal of Economic Growth 6(3), 167-86.

Meade, J. E.: 1961, Mauritius: A case study in Malthusian economics, The Economic Journal 71(283), 521-534.

Nath, S. and Madhoo, N.: 2008, A shared growth story of economic success: the case of mauritius, in B. J. Ndulu, S. A. O'Connell, R. H. Bates, P. Collier and C. C. Soludo (eds), The Political Economy of Economic Growth in Africa, 19602000, Vol. 2 of Cambridge Books, Cambridge University Press.

Ndulu, B. J. and O'Connell, S. A.: 1999, Governance and growth in Sub-Saharan Africa, Journal of Economic Perspectives 13(3), 41-66.

Ndulu, B. J. and O'Connell, S. A.: 2009, Policy plus: African growth performance 1960-2000, in B. J. Ndulu, S. A. O'Connell, R. H. Bates, P. Collier and C. C. Soludo (eds), The Political Economy of Economic Growth in Africa, 1960-2000, Vol. 1 of Cambridge Books, Cambridge University Press. 
Nunn, N.: 2008, The long-term effects of Africa's slave trades, The Quarterly Journal of Economics 123(1), 139-176.

Platteau, J.-P.: 2009, Institutional obstacles to African economic development: State, ethnicity and custom, Journal of Economic Behavior $\&$ Organization 71(3), 669-689.

Pritchett, L.: 2000, The tyranny of concepts: CUDIE (cumulated, depreciated, investment effort) is not capital, Journal of Economic Growth 5(4), 361-384.

Psacharopoulos, G.: 1994, Returns to investment in education: A global update, World Development 22, 1325-1343.

Psacharopoulos, G. and Patrinos, H. A.: 2004, Returns to investment in education: A further update, Education Economics 12(2), 111-134.

Ridler, N. B.: 1985, Comparative advantage as a development model: the ivory coast, The Journal of Modern African Studies 23, 407-417.

Ridler, N. B.: 1988, The caisse de stabilisation in the coffee sector of the ivory coast, World Development 16(12), 1521-1526.

Rodrik, D.: 1999, Where did all the growth go? external shocks, social conflict, and growth collapses, Journal of Economic Growth 4(4), 385-412.

Rodrik, D., Subramanian, A. and Trebbi, F.: 2004, Institutions rule: The primacy of institutions over geography and integration in economic development, Journal of Economic Growth 9(2), 131-165.

Sachs, J. D. and Warner, A. M.: 1997, Sources of slow growth in African economies, Journal of African Economies 6(3), 335-76.

Sachs, J. D., Warner, A., slund, A. and Fischer, S.: 1995, Economic reform and the process of global integration, Brookings Papers on Economic Activity 1995(1), 1118.

Senhadji, A.: 2000, Sources of economic growth: An extensive growth accounting exercise, IMF Staff Papers 47, 129-158.

Sickles, R. C.: 2012, World productivity growth and income inequality, mimeo, Rice University.

Silverman, B. W.: 1986, Density Estimation for Statistics and Data Analysis, Chapman and Hall. 
Simar, L. and Wilson, P. W.: 1998, Sensitivity analysis of efficiency scores: How to bootstrap in nonparametric frontier models, Management Science 44, 49-61.

Simar, L. and Wilson, P. W.: 1999, Estimating and bootstrapping Malmquist indices, European Journal of Operational Research 115(3), 459-471.

Subramanian, A.: 2009, The mauritian success story and its lessons, Working Papers UNU-WIDER Research Paper, World Institute for Development Economic Research (UNU-WIDER).

Subramanian, A. and Roy, D.: 2001, Who can explain the mauritian miracle: Meade, romer, sachs, or rodrik?, IMF Working Papers 01/116, International Monetary Fund.

Tahari, A., Ghura, D., Akitoby, B. and Brou Aka, E.: 2004, Sources of growth in Sub-Saharan Africa, IMF Working Papers 04/176, International Monetary Fund.

UNESCO: 2010, Civil War Exposure And School Enrollment: Evidence From The Mozambican Civil War, Technical Paper No. 7, UNESCO Institute for Statistics.

Weil, D. N.: 2008, Economic Growth, Pearson Education, Addison Wesley.

Weir, S. and Knight, J.: 2000, Education externalities in rural ethiopia: Evidence from average and stochastic frontier production functions, Technical report, CASE, University of Oxford.

Werker, E. and Beganovic, J.: 2011, Liberia: A case study, Technical report, Prepared for the International Growth Center Workshop on Growth in Fragile States.

World Bank: 1981, World Development Report, World Bank.

Zelenyuk, V.: 2011, Estimating and bootstrapping Malmquist indices, European Journal of Operational Research 212(1), 190-198. 
Table 2: Productivity and Statistical Significance of the Percentage Contributions to Labor Productivity Change in African Countries, 1970-2007 $(* * * * * / *$ IMPLIES SIGNIFICANCE AT 1\%/5\%/10\% LEVEL)

\begin{tabular}{|c|c|c|c|c|c|c|}
\hline \# & Country & $\begin{array}{r}\text { Productivity } \\
\text { change }\end{array}$ & $\begin{array}{r}(E F F-1) \\
\times 100\end{array}$ & $\begin{array}{r}(T E C H-1) \\
\times 100\end{array}$ & $\begin{array}{r}(K A C C-1) \\
\times 100\end{array}$ & $\begin{array}{r}(H A C C-1) \\
\times 100\end{array}$ \\
\hline 1 & Algeria & -14.49 & $-74.89 * * *$ & 4.40 & 3.51 & $215.17 * * *$ \\
\hline 2 & Benin & 23.52 & $-32.62^{* * *}$ & 0.00 & 22.73 & $49.38 * * *$ \\
\hline 3 & Botswana & 579.91 & 0.01 & 3.34 & $143.08^{* * *}$ & $170.64^{* * *}$ \\
\hline 4 & Burundi & -23.15 & $-73.62 * * *$ & 0.00 & 149.14 & $16.92 * * *$ \\
\hline 5 & Cameroon & 50.61 & $-43.99 * * *$ & 0.00 & 64.19 & $63.78^{* * *}$ \\
\hline 6 & $\begin{array}{l}\text { Central African } \\
\text { Republic }\end{array}$ & -29.44 & $-47.11 * * *$ & 0.00 & -11.76 & $51.2 * * *$ \\
\hline 7 & Congo & 60.70 & $-19.21 * *$ & 0.00 & 27.15 & $56.44^{* * *}$ \\
\hline 8 & Cote d'Ivoire & -7.20 & $-28.29 * * *$ & 0.00 & -0.94 & $30.64 * * *$ \\
\hline 9 & Egypt & 164.72 & $-24.51 * *$ & 0.00 & $61.48^{*}$ & $117.15^{* * *}$ \\
\hline 10 & Gabon & 1.74 & $-63.59 * * *$ & 0.00 & 33.79 & $108.84^{* * *}$ \\
\hline 11 & Gambia & 2.74 & $-59.38 * * *$ & 0.00 & 71.17 & $47.78 * * *$ \\
\hline 12 & Ghana & 20.87 & -5.53 & 0.00 & -17.29 & $54.69 * * *$ \\
\hline 13 & Kenya & 7.45 & $-39.79 * * *$ & 0.00 & 4.87 & $70.16 * * *$ \\
\hline 14 & Lesotho & 180.57 & $-34.1^{* * *}$ & 0.00 & $261.4^{*}$ & 17.81 \\
\hline 15 & Liberia & -78.52 & $-91.71 * * *$ & 0.00 & $82.78^{*}$ & $41.7 * * *$ \\
\hline 16 & Malawi & 134.71 & $42.14^{* *}$ & 0.00 & 5.71 & $56.2^{* * *}$ \\
\hline 17 & Mali & 110.75 & -8.64 & 0.00 & $89.47^{*}$ & $21.75^{* * *}$ \\
\hline 18 & Mauritania & 21.15 & $-37.68^{* * *}$ & 0.00 & 42.06 & $36.85 * * *$ \\
\hline 19 & Mauritius & 214.61 & $73.75 * * *$ & 6.77 & $22.26^{*}$ & $38.72^{* * *}$ \\
\hline 20 & Morocco & 40.11 & $-49.32 * * *$ & 8.07 & 32.95 & $92.41 * * *$ \\
\hline 21 & Mozambique & 89.87 & 2.02 & 0.00 & 80.34 & 3.2 \\
\hline 22 & Namibia & 14.86 & $-40.17 * * *$ & 5.58 & 12.54 & $61.6^{* * *}$ \\
\hline 23 & Niger & -34.84 & $-51.33 * * *$ & 0.00 & 15.21 & $16.21^{* * *}$ \\
\hline 24 & Rwanda & -2.83 & $-67.05 * * *$ & 0.00 & 132.89 & $26.61 * * *$ \\
\hline 25 & Senegal & -6.88 & $-57.97 * * *$ & 0.00 & 66.99 & $32.67 * * *$ \\
\hline 26 & Sierra Leone & -25.18 & $-48.8^{* * *}$ & 0.00 & 9.51 & $33.44^{* * *}$ \\
\hline 27 & South Africa & 29.82 & $-31.37 * * *$ & 5.06 & 9.17 & $64.93 * * *$ \\
\hline 28 & Sudan & 88.98 & $-72.32 * * *$ & 4.14 & $392.22^{*}$ & $33.21 * * *$ \\
\hline 29 & Swaziland & 198.25 & $-62.61 * * *$ & 2.15 & $406.36 *$ & $54.24 * * *$ \\
\hline 30 & Tanzania & 56.00 & $-36.55 * * *$ & 0.00 & 95.49 & $25.77 * * *$ \\
\hline 31 & Togo & -34.69 & $-64.78^{* * *}$ & 0.00 & 5.92 & $75.07 * * *$ \\
\hline 32 & Tunisia & 139.61 & -21.47 & 7.36 & 7.82 & $163.59 * * *$ \\
\hline 33 & Uganda & 12.41 & $-42.08 * * *$ & 0.00 & 41.84 & $36.84^{* * *}$ \\
\hline 34 & Zambia & -32.52 & $-45.49 * * *$ & 2.58 & -11.72 & $36.7^{* *}$ \\
\hline 35 & Zimbabwe & -57.92 & $-79.11 * * *$ & 3.99 & 5.06 & $84.36^{* * *}$ \\
\hline 36 & Average & 54.18 & $-38.21 * * *$ & 1.53 & 67.35 & $60.19 * * *$ \\
\hline 37 & Weighted Average & 68.91 & $-36.28 * * *$ & 3.07 & 47.55 & $92.48^{* * *}$ \\
\hline
\end{tabular}


Table 3: Mean and Weighted Mean of Productivity and Percentage Contributions to Labor Productivity Change in Africa (***/**** IMPLIES SIGNIFICANCE AT 1\%/5\%/10\% LEVEL)

\begin{tabular}{|c|c|c|c|c|c|c|}
\hline Period & Statistic & $\begin{array}{r}\text { Productivity } \\
\text { change }\end{array}$ & $\begin{array}{r}(E F F-1) \\
\times 100\end{array}$ & $\begin{array}{r}(T E C H-1) \\
\times 100\end{array}$ & $\begin{array}{r}(K A C C-1) \\
\times 100\end{array}$ & $\begin{array}{r}(H A C C-1) \\
\times 100\end{array}$ \\
\hline \multirow{2}{*}{$1970-1979$} & Average & 20.84 & $-22.41 * * *$ & 1.80 & $45.5 * * *$ & $13.69 * * *$ \\
\hline & $\begin{array}{l}\text { Weighted } \\
\text { Average }\end{array}$ & 16.37 & $-17.45^{*}$ & 4.12 & 22.22 & $16.26 * * *$ \\
\hline \multirow{2}{*}{ 1980-1989 } & Average & 5.78 & $-9.13^{* * *}$ & 0 & 1.9 & $15.15^{* * *}$ \\
\hline & $\begin{array}{l}\text { Weighted } \\
\text { Average }\end{array}$ & 8.83 & $-12.77^{* * *}$ & 0 & 0.68 & $25.21^{* * *}$ \\
\hline \multirow{2}{*}{ 1990-1999 } & Average & -1.06 & $-8.43^{* * *}$ & 0 & -1.46 & $10.85 * * *$ \\
\hline & $\begin{array}{l}\text { Weighted } \\
\text { Average }\end{array}$ & 2.85 & $-8.62^{* *}$ & 0 & -0.51 & $14.24^{* * *}$ \\
\hline \multirow{2}{*}{$2000-2007$} & Average & 13.04 & -0.64 & 0 & 5.85 & $7.52 * * *$ \\
\hline & $\begin{array}{l}\text { Weighted } \\
\text { Average }\end{array}$ & 17.19 & 0.41 & 0 & 8.38 & $8.16 * * *$ \\
\hline \multirow{2}{*}{$1970-2007$} & Average & 54.18 & $-38.21 * * *$ & 1.53 & 67.35 & $60.19 * * *$ \\
\hline & $\begin{array}{l}\text { Weighted } \\
\text { Average }\end{array}$ & 68.91 & $-36.28 * * *$ & 3.07 & 47.55 & $92.48 * * *$ \\
\hline
\end{tabular}


Table 4: Mean and Weighted Mean of Productivity and Percentage Contributions to Labor Productivity Change by Groups, 1970-2007 $\left(* * * / * *{ }^{*}\right.$ IMPLIES SIGNIFICANCE AT $1 \% / 5 \% / 10 \%$ LEVEL $)$

\begin{tabular}{|c|c|c|c|c|c|c|}
\hline Group & Statistic & $\begin{array}{r}\text { Productivity } \\
\text { change }\end{array}$ & $\begin{array}{r}(E F F-1) \\
\times 100\end{array}$ & $\begin{array}{r}(T E C H-1) \\
\times 100\end{array}$ & $\begin{array}{r}(K A C C-1) \\
\times 100\end{array}$ & $\begin{array}{r}(H A C C-1) \\
\times 100\end{array}$ \\
\hline $\mathrm{OECD}^{\S}$ & $\begin{array}{l}\text { Average } \\
\text { Weighted } \\
\text { Average }\end{array}$ & $\begin{array}{r}100.42 \\
89.96\end{array}$ & $\begin{array}{l}-11.97 * * * \\
-15.98 * * *\end{array}$ & $\begin{array}{r}17.77^{* * *} \\
14.64^{* *}\end{array}$ & $\begin{array}{l}71.64^{* * *} \\
78.61^{* * *}\end{array}$ & $\begin{array}{l}15.33^{* * *} \\
12.12^{* * *}\end{array}$ \\
\hline Americas $^{\dagger}$ & $\begin{array}{l}\text { Average } \\
\text { Weighted } \\
\text { Average }\end{array}$ & $\begin{array}{l}22.78 \\
24.90\end{array}$ & $\begin{array}{r}-22.3^{* * *} \\
-19.37^{* * *}\end{array}$ & $\begin{array}{l}5.14 \\
5.64\end{array}$ & $\begin{array}{r}33.63^{* * *} \\
28.66\end{array}$ & $\begin{array}{l}14.21^{* * *} \\
14.32^{* * *}\end{array}$ \\
\hline Asia $\ddagger$ & $\begin{array}{l}\text { Average } \\
\text { Weighted } \\
\text { Average }\end{array}$ & $\begin{array}{l}231.28 \\
589.43\end{array}$ & $\begin{array}{r}2.36^{*} \\
15.85^{* * *}\end{array}$ & $\begin{array}{l}7.34 \\
6.80\end{array}$ & $\begin{array}{r}159.79^{* *} \\
367.82^{* * *}\end{array}$ & $\begin{array}{l}18.45^{* * *} \\
16.61^{* * *}\end{array}$ \\
\hline East Asia & $\begin{array}{l}\text { Average } \\
\text { Weighted } \\
\text { Average }\end{array}$ & $\begin{array}{l}409.93 \\
739.69\end{array}$ & $\begin{array}{r}2.69 * * * \\
37.67 * * *\end{array}$ & $\begin{array}{l}44.45 \\
28.85\end{array}$ & $\begin{array}{r}191.81^{*} \\
320.41 * * *\end{array}$ & $\begin{array}{l}22.99 * * * \\
14.78 * * *\end{array}$ \\
\hline
\end{tabular}

$\S$ (OECD as of 1970) Austria, Belgium, Canada, Denmark, Finland, France, Greece, Iceland, Ireland, Italy, Japan, Luxembourg, Netherlands, Norway, Portugal, Spain, Sweden, Switzerland, Turkey, United Kingdom, United States

$\dagger$ Argentina, Bolivia, Brazil, Chile, Colombia, Costa Rica, Ecuador, El Salvador, Guatemala, Haiti, Honduras, Jamaica, Nicaragua, Panama, Paraguay, Peru, Trinidad and Tobago, Uruguay, Venezuela

$\ddagger$ Bangladesh, China, Fiji, Hong Kong, India, Indonesia, Iran, Japan, Jordan, Korea, Malaysia, Pakistan, Papua New Guinea, Philippines, Singapore, Sri Lanka, Syria, Taiwan, Thailand

ף China, Hong Kong, Indonesia, Japan, Korea, Malaysia, Singapore, Taiwan, Thailand 